\title{
Aesthetic and Functional Outcomes of Open versus Closed Septorhinoplasty in Deviated Nose Deformity
}

\author{
Seyed Mousa Sadr Hosseini ${ }^{1}$, Mohammad Sadeghi ${ }^{1}$, Babak Saedi $^{{ }^{*}}$, Amin Safavi ${ }^{2}$, \\ Ghasem Reza Hedaiati ${ }^{2}$ \\ ${ }^{1}$ Otolaryngology Department, Tehran University of Medical Sciences, Tehran, Iran \\ ${ }^{2}$ Tehran University of Medical Sciences, Tehran, Iran \\ Email: "saedi@tums.ac.ir
}

Received March 1, 2012; revised April 5, 2012; accepted April 30, 2012

\begin{abstract}
Background: Over the years, an optimal surgical method for septorhinoplasty in deviated nose as a challenging problem was the one of common interest of plastic surgeon; the purpose of this study is to compare outcomes of open and closed methods of septorhinoplasty in patients with deviated noses. Methods: Through a prospective study, we selected seventy patients with deviated nose. Based on their deviation severity, they underwent open or closed septorhinoplasty. Patients were evaluated for deviation angles of nasal bony and cartilage components, nasal projection, nasolabial angle, nasofacial angle, and nasofrontal angle; for which three standard photos were captured pre and postoperatively. Finally the outcomes were analyzed according to their surgical methods. Results: Closed septorhinoplasty could grant a mean 11 degrees correction to nasal bony component and a mean 8.6 degrees correction to cartilage component. That's while open septorhinoplasty could bring a mean 19.5 degrees deviation correction to the bony component and a mean 12.5 degrees deviation correction to the cartilage component. Cosmetic angles were not improved significantly after the surgery, maybe because of complicated deformities our series of patients had. Conclusion: Open septorhinoplasty resulted in better cosmetic and functional outcomes than the closed method.
\end{abstract}

Keywords: Deviated Nose; Rhinoplasty; Septorhinoplasty; Cosmetic; Function

\section{Introduction}

Nasal deviation, termed as "deviated nose" in medical literature, is a complex deformity involving almost all structures within the nose [1,2]. Deviated nose or crooked nose can be defined by drawing a line virtually drawn from mid-glabella to pogonion (glabella-to-pogonion line), passes through nasal bridge, nasal tip, and cupids' bow and finally incisive teeth; nasal deviation from this line to either side, would be defined as "deviated nose" [2-4].

Anatomically, nasal deviation may be categorized into the following deformities: "tilt deformity", "S-shaped deformity", and "C-shaped deformity" or a combination of them [4]. Occasionally, nasal deviation is accompanied by other facial deformities, too [4,5]. The bony and the cartilage components of nose, together, form the functional nasal structure; and they are both subject to deviation, especially nasal septum. Nasal septum has a major role in forming the "nasal valve" with caudal portions of lateral nasal cartilages; even a slight change to its shape or length may affect nasal physiologic function through altering the nasal valve diameter; this ends up to

\footnotetext{
"Corresponding author.
}

a variety of diseases such as: nasal obstruction, sinus disease, structural disorders and nasal cosmetic appearance. According to this, septal and nasal valve correction is the basic principle in treatment of a deviated nose $[6,7]$. The real incidence of deviated nose is unclear, but probably like septal deviation different among countries and ethnicity [4].

Etiologically, deviated nose is almost always caused by nasal trauma; although many of those deformities without known causing trauma are incorrectly referred to as congenital or evolutional deformities; it's now believed that even those deviations too, are caused by tiny fractures during intrauterine life, obstetric traumas, or traumas in infancy and early childhood. Whatever the cause of deviated nose is, this deformity precipitates in structural asymmetry leading to a variety of problems to either or both nasal aesthetic and function [8]. This fact ascertains the need for surgical intervention.

Surgeons might be so obsessive about the cosmetic outcome, because this is maybe the only thing that satisfies their patients best; but sometimes patients favor a better functional outcome than the aesthetic; the truth is that both aesthetic and function have their own values, 
one gives a better self-image and one gives a better quality of life, so the effort should be put on the selection of a surgical method which best fulfills the ideals for both aesthetic and function. Certainly, they are not easily achievable, and keeping both at their optimums is the art of a good surgeon. Thus, septorhinoplasty in patients with deviated nose, more as a therapeutic operation than a cosmetic, should pay attention to nasal function as much as nasal aesthetic [9-11].

There are a variety of surgical techniques for septorhinoplasty, and no unique method is applicable to all patients [10,12-15]; it's on the surgeon to choose the best that ends up to a better possible outcome. This study aims to investigate the outcomes of open and closed septorhinoplasty in patients with deviated nose and the way each affect on nasal cosmetics and function.

\section{Subjects and Methods}

\subsection{Study Subjects}

We designed a prospective study in which 70 patients with "deviated nose" entered. The patients were selected among those referred to ENT-clinic of a tertiary healthcare center (Imam Khomeini Hospital, an affiliate of Tehran University of Medical Sciences). They were all indicated candidates for septorhinoplasty with obvious external nasal deviation. Both cosmetic and functional problems were present in approximately all these patients. Operation method was chosen upon deviation severity. Patients with mild to moderate deviations underwent closed septorhinoplasty and those with moderate to severe deviations had open septorhinoplasty. The study started in 2007 and finished in 2011.

\subsection{Inclusion Criteria}

Patients with deviated nose, who were selected for septorhinoplasty and had followed up at least 12 months after their surgery, were entered to the study.

\subsection{Exclusion Criteria}

None of our patients suffered from systemic diseases such as sarcoidosis or Wegner granulomatosis and psychological problems.

Moreover, pregnant patients, patients younger than 18 years, immunedeficient patients, and cases with malignancy were excluded from this study.

Accordingly, revision cases were disqualified.

\subsection{Ethical Approval}

The protocol of this study was approved by the Institutional Review Board of the Tehran University of Medical Science. Detailed information about the study was given to the participants and a written informed consent was obtained from each one. All aspects of the study were conducted according to the Declaration of Helsinki.

\subsection{Variables}

Pre-op evaluations: A questionnaire consisting of two parts of pre-op and post-op data was made; patients filled out their demographic data and their chief complaints. They also graded their pre-op symptoms' severity as mild, moderate or severe. A complete physical examination was performed by a physician in-charge, and positive findings were reflected into the sheets.

Deviation angles of bony and cartilage components: Three standard photos (a full-view, a side-view and a nasal base-view) were captured once before the surgery and once after, at follow-ups. The values required for deviation measurements were obtained from the photos through computer analysis. This was based on the "light reflex" as a quantitative measure for nasal deviation. Usually, the light reflex on a plane dorsum of a non-deviant nose is a straight and non-angled line; but in deviated noses, the light reflex makes an angle with glabella-to-pogonion line; this was considered as deviation angle. By putting these pre and post-op values into comparison, the relative deviation correction angle would be defined. The values were measured for both bony and cartilage components distinctly.

According to computer analysis, noses with $0^{\circ}$ deviation were considered as perfect, whereas $0^{\circ}-10^{\circ}$ were treated as mild deviation, $10^{\circ}-20^{\circ}$ as intermediate, and $20^{\circ}-30^{\circ}$ as severe.

Photographs were taken with a Canon power shot S5 digital camera with a Canon X12 Zoom lens to ensure proper and uniform photographic size. We used the same position of patients and photographer, according to the Frankfort horizontal line at a fixed distance of $1 \mathrm{~m}$. The facial section between the horizontal planes running above the eyebrows and below the mentum was copied from the postoperative photograph.

Aesthetic indexes were measured using Adobe Photoshop 7 software which provided an accurate analysis of the same facial sections in the preoperative and postoperative photographs [16].

Nasal projection: according to Goode's method, nasal projection is a proportion, defined as the length of alar point-to-nasal tip line divided by the length of the nasion-to-nasal tip line. The normal value for this proportion is 0.55 to 0.60 .

Nasolabial angle: is the angle defined by subnasale-to-labrale superius line intercepting with columellar point-to-subnasale line. Its normal range is within $90^{\circ}$ $100^{\circ}$ for men and $100^{\circ}-110^{\circ}$ for women. 
Nasofacial angle: is the angle made by nasion-to-tip line and glabella-to-pogonion line. The ideal for this angle is $36^{\circ}$, although $30^{\circ}-40^{\circ}$ is an acceptable range.

Nasofrontal angle: is simply the angle defined by nasion-to-glabella line intersecting with nasion-to-tip line. Normal range for this angle is within $115^{\circ}-130^{\circ}$ [16] (Figure 1).

Patients' satisfaction rates: postoperatively at the end of evaluation, patients were asked to determine their satisfaction rates with their cosmetic and functional outcomes, separately; for each outcome they chose one of the following options: 1) fully satisfied with the outcome; 2) relatively satisfied with the outcome; 3) Just satisfied with the outcome; 4) relatively unsatisfied with the outcome; and 5) fully unsatisfied with the outcome.

\subsection{Method of Surgery}

Septorhinoplasty was performed in either open or closed methods. Putting the patients into these groups was based on their deviation severity; patients with mild to moderate deviation, especially in bony parts would undergo closed septorhinoplasty, while those with moderate to severe deviation would have open surgeries. Accordingly, if patients needed spreader grafts for correction of dorsum and valve problems, the open approach would be chosen.

All procedures were performed by one of the senior authors under general anesthesia. Additionally, internal lateral osteotomy was performed in all procedures. No

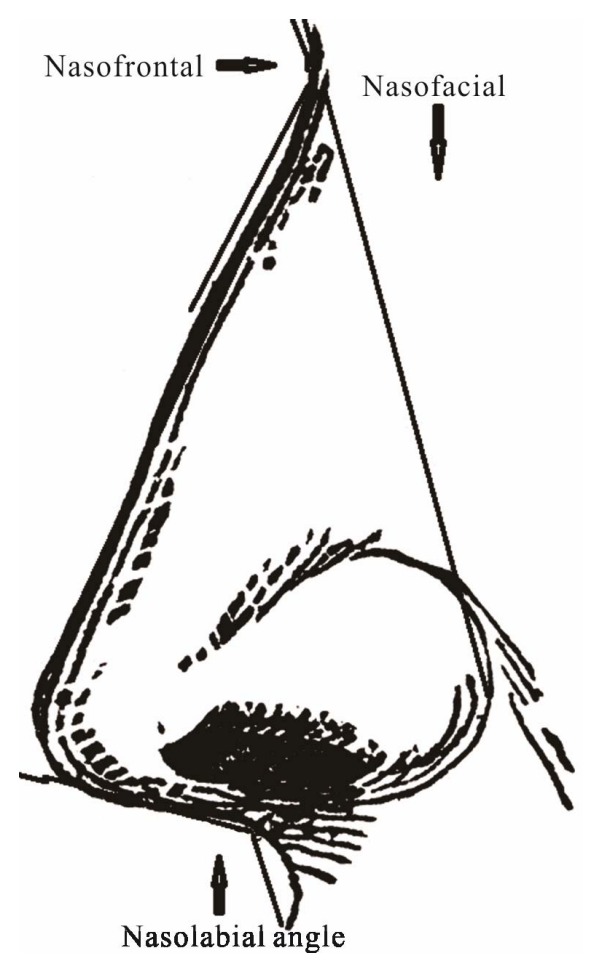

Figure 1. Nasolabial, nasofrontal and nasofacial angle. packing was used. Moreover, antibiotic prophylaxis (Cephalexin $500 \mathrm{mg} / \mathrm{QID}$ for five days) was given to all patients and the only prescribed analgesic was acetaminophen. Subsequently, their nasal splints were removed after 21 days but tapings were continued for 4 weeks thereafter.

In both groups, the correction of deviate septum was performed primarily by using of all techniques. Also, in severely deviated septum extra-corporeal septoplasty was conducted. Additionally, columellar strut was use in all cases. Accordingly, in all open cases bilateral spreader grafts were used.

\subsection{Statistical Method}

In addition to demographic data and satisfaction degrees rated by patients in follow-up visits, other effective cosmetic factors were extracted from photos analyzed by computer, to determine the interrelationship of surgical method with the cosmetic and functional outcomes. These factors were pre and post-op deviation angles of nasal bony and cartilage components, nasal projection, nasolabial angle, nasofacial angle, and nasofrontal angle. Data were analyzed by t-Test and Wilcoxon Signed Ranks Test, using SPSS (11.5). $P$ values less than 0.05 were considered as significant.

\section{Results}

Among 70 patients, completed our post-op survey; from which, 40 (57.1\%) had undergone closed septorhinoplasty and the rest 30 (42.9\%) had open surgeries.

We had 56 (80\%) male patients and 24 (20\%) females. The average age was $23.3 \pm 4.5$ years, ranging from 18 to 36. 57 patients (81.4\%) reported previous trauma to their noses, while the rest could not specify a cause.

The average follow-up period was $14.2 \pm 4.3$ months with a minimum of 12 and a maximum of 24 .

In patients' own point of view, chief complaints included nasal obstructive symptoms in 50 patients (71.4\%) and cosmetic problem with nasal deviation in 16 (22.9\%). Only one patient had symptoms related to chronic sinusitis, such as purulent post-nasal drip, severe nasal congestion and facial fullness.

45 patients (64\%) graded their pre-op symptoms as severe, $14(20 \%)$ as moderate and $11(16 \%)$ as mild.

Deviation correction of bony and cartilage components of the nose were measured by light reflex, and patients' data was analyzed in groups according to surgical method.

\subsection{Septorhinoplasty Outcomes in Closed Method Group}

The mean value for pre-op bony component deviation angle was $17.4 \pm 6$ degrees, which was postoperatively reduced to $6.4 \pm 5$ degrees (t-Test, $P=0.0001)$. Closed 
method also could reduce cartilage component deviation angle from $16.5 \pm 6.3$ degrees to $8 \pm 6.2$ degrees (t-Test, $P=0.099$ ).

\subsection{Septorhinoplasty Outcomes in Open Method Group}

In this group, pre-op mean deviation angle of bony component was $25 \pm 3.7$ degrees, while the same value was plummeted to $5.4 \pm 5$ degrees after the surgery (t-Test, $P$ $=0.0001)$. Of cartilage component, a mean $18 \pm 5.5$ degrees pre-op deviation angle had cut to $5.3 \pm 3$ degrees, postoperatively (t-Test, $P=0.044$ ).

\subsection{Deviation Correction Rates}

Closed septorhinoplasty could grant a mean $11 \pm 7$ degrees correction to nasal bony component (t-Test, $P=$ $0.004)$ and a mean $8.6 \pm 6.5$ degrees correction to cartilage component (t-Test, $P=0.0001$ ). That's while open septorhinoplasty resulted in a mean $19.5 \pm 6$ degrees deviation correction to the bony component (t-Test, $P=$ $0.005)$ and a mean $12.5 \pm 4.3$ degrees deviation correction to the cartilage component (t-Test, $P=0.0001$ ).

Table 1 outlines number of patients in pre and post-op deviation severity groups, for both bony and cartilage components.

\subsection{Cosmetic Angles}

Table 2 outlines numbers of patients in each angle limit group.

Both closed and open septorhinoplasty had corrected these cosmetic angles only to some extent, and outcome values in comparison to pre-ops were not significantly changed (according to Wilcoxon Signed Ranks Test).

Table 1. Deviation severity according to light reflex investigation.

\begin{tabular}{|c|c|c|c|c|}
\hline \multirow[b]{2}{*}{ Component/OP type } & \multirow[b]{2}{*}{ Time } & \multicolumn{3}{|c|}{$\begin{array}{l}\text { No. of Patients in } \\
\text { Severity Groups }\end{array}$} \\
\hline & & Mild & Moderate & Severe \\
\hline \multirow{2}{*}{$\begin{array}{c}\text { Bony Component, } \\
\text { Closed Surgery }\end{array}$} & Pre-op & 6 & 22 & 12 \\
\hline & Post-op & 31 & 9 & 0 \\
\hline \multirow{2}{*}{$\begin{array}{c}\text { Bony Component, } \\
\text { Open Surgery }\end{array}$} & Pre-op & 0 & 3 & 27 \\
\hline & Post-op & 27 & 3 & 0 \\
\hline \multirow{2}{*}{$\begin{array}{l}\text { Cartilage } \\
\text { Component, } \\
\text { Closed Surgery }\end{array}$} & Pre-op & 9 & 16 & 15 \\
\hline & Post-op & 32 & 8 & 0 \\
\hline \multirow{2}{*}{$\begin{array}{c}\text { Cartilage } \\
\text { Component, } \\
\text { Open Surgery }\end{array}$} & Pre-op & 1 & 20 & 9 \\
\hline & Post-op & 28 & 2 & 0 \\
\hline
\end{tabular}

Table 2. Limits of cosmetic angles according to light reflex investigation.

\begin{tabular}{|c|c|c|c|c|c|}
\hline \multirow[b]{2}{*}{ Angle/Operation } & \multicolumn{5}{|c|}{ No. of Patients in Limit Groups } \\
\hline & Time & Exceeding Normal Limits & Within Normal Limits & Below than Normal Limits & $P$ Values \\
\hline \multirow{2}{*}{ Nasal Tip Projection/Closed } & Pre-op & 9 & 28 & 3 & \multirow{2}{*}{0.157} \\
\hline & Post-op & 3 & 28 & 9 & \\
\hline \multirow{2}{*}{ Nasal Tip Projection/Open } & Pre-op & 9 & 9 & 12 & \multirow{2}{*}{0.99} \\
\hline & Post-op & 3 & 20 & 6 & \\
\hline \multirow[b]{2}{*}{ Nasolabial/Closed } & Pre-op & 9 & 27 & 4 & \multirow[b]{2}{*}{0.763} \\
\hline & Post-op & 12 & 18 & 12 & \\
\hline \multirow{2}{*}{ Nasolabial/open } & Pre-op & 12 & 6 & 12 & \multirow{2}{*}{0.763} \\
\hline & Post-op & 3 & 22 & 5 & \\
\hline \multirow{2}{*}{ Nasofacial/Closed } & Pre-op & 0 & 36 & 4 & \multirow{2}{*}{0.655} \\
\hline & Post-op & 3 & 33 & 4 & \\
\hline \multirow{2}{*}{ Nasofacial/Open } & Pre-op & 0 & 24 & 6 & \multirow{2}{*}{0.317} \\
\hline & Post-op & 0 & 28 & 2 & \\
\hline \multirow[b]{2}{*}{ Nasofrontal/Closed } & Pre-op & 37 & 3 & 0 & \multirow[b]{2}{*}{0.317} \\
\hline & Post-op & 28 & 12 & 0 & \\
\hline \multirow{2}{*}{ Nasofrontal/Open } & Pre-op & 30 & 0 & 0 & \multirow{2}{*}{0.157} \\
\hline & Post-op & 24 & 6 & 0 & \\
\hline
\end{tabular}




\subsection{Patients' Satisfaction Rates}

Patients' post-op satisfaction rates with their cosmetic and functional outcomes were acquired in their last follow-up visit. Tables $\mathbf{3}$ and $\mathbf{4}$ outline these values:

\subsection{Complications}

As post-op complications, open surgery precipitated in columella retraction in one patient, while closed surgery led to septal deviation in 3 patients affecting their nasal valve function; these 3 were indicated to undergo revisions for septal and nasal valve correction.

Table 3. Patients' satisfaction rate with their cosmetic outcome.

\begin{tabular}{ccccc}
\hline \multirow{2}{*}{$\begin{array}{c}\text { Degree of } \\
\text { Satisfaction }\end{array}$} & $\begin{array}{c}\text { Type of } \\
\text { Procedure }\end{array}$ & Number & & \multicolumn{2}{c}{ Sum } \\
\cline { 3 - 5 } Fully Satisfied & Open & 9 & 36 & 51.4 \\
& Close & 27 & & \\
Relatively Satisfied & Open & 18 & 30 & 42.9 \\
& Close & 12 & & \\
Just Satisfied & Open & 3 & & 5.7 \\
Relatively & Close & 1 & & \\
Unsatisfied & Open & 0 & 0 & 0 \\
Close & 0 & & \\
Fully Unsatisfied & Open & 0 & 0 & 0 \\
Total & Close & 0 & & \\
\hline
\end{tabular}

Table 4. Patients' satisfaction with their functional outcome.

\begin{tabular}{|c|c|c|c|c|}
\hline \multirow{2}{*}{$\begin{array}{c}\text { Degree of } \\
\text { Satisfaction }\end{array}$} & \multirow{2}{*}{$\begin{array}{c}\text { Type of } \\
\text { Procedure }\end{array}$} & \multirow{2}{*}{ Percent } & \multicolumn{2}{|c|}{ Sum } \\
\hline & & & Amount & Percent \\
\hline \multirow{2}{*}{ Fully Satisfied } & Open & 14 & \multirow{2}{*}{24} & \multirow{2}{*}{34.3} \\
\hline & Close & 10 & & \\
\hline \multirow{2}{*}{$\begin{array}{l}\text { Relatively } \\
\text { Satisfied }\end{array}$} & Open & 13 & \multirow{2}{*}{36} & \multirow{2}{*}{51.4} \\
\hline & Close & 23 & & \\
\hline \multirow{2}{*}{ Just satisfied } & Open & 3 & \multirow{2}{*}{10} & \multirow{2}{*}{14.3} \\
\hline & Close & 7 & & \\
\hline \multirow{2}{*}{$\begin{array}{l}\text { Relatively } \\
\text { Unsatisfied }\end{array}$} & Open & 0 & \multirow{2}{*}{0} & \multirow{2}{*}{0} \\
\hline & Close & 0 & & \\
\hline \multirow{2}{*}{$\begin{array}{c}\text { Fully } \\
\text { Unsatisfied }\end{array}$} & Open & 0 & \multirow{2}{*}{0} & \multirow{2}{*}{0} \\
\hline & Close & 0 & & \\
\hline Total & & & 70 & 100 \\
\hline
\end{tabular}

\section{Discussion}

Deviated nose deformity as a common nasal deformity considers as a challenging problem to correct. Over the year, many surgeons tried to correct this abnormality, thus different approaches recommended by various authors $[3,8,12,14,15,17]$. Among diverse controversial issues, the best method of surgery was interested by so many authors. However, most of surgeons advocate open approach to correct deviated nose deformity, some others still use closed approach for minimal deformities [9].

Male patients had more severe deviations than females, and all open surgery candidates were male.

Patients' chief complaints were about cosmetic and functional problems, up to $71.4 \%$ of them had problems with their nasal function and mainly obstructive symptoms, that's while the rest $22.9 \%$ specified cosmetic problems as their main motive for operation. Thus, this statistics showed that nasal obstruction is the patients' main concern and should be considered on every surgery.

Both open and closed methods of septorhinoplasty could achieve high satisfaction rates from patients; up to $80 \%$ of patients had rated their functional outcomes as fully or relatively satisfying, while $88 \%$ chose the same satisfaction rates for their cosmetic outcomes.

To select either open or closed method of septorhinoplasty, we grouped the patients based on the severity of their nasal deviation; therefore 40 (57.1\%) patients were put into closed septorhinoplasty group. Regardless of the more severe deformities and deviations which were present in those who underwent open surgery, functional outcomes were much better in this group. That means, no one reported obstructive symptoms after open surgery; while in closed septorhinoplasty group, 3 patients had obstructive symptoms and moderate to severe septal deviation in physical examination, postoperatively.

The authors like Gunter et al. [17] think that the main step of deviated nose deformity correction is straitening of nasal septum. Accordingly, the better exposure of septum in open approach can be one explanation for difference in our results [7]. Moreover, spreader graft usage is the other effective technique to straitening of dorsum and camouflage the depressed parts of deformity, which can be done more easily in open approach [1].

$22.9 \%$ of patients specified cosmetic problems as their chief-complaints, they also had functional problems though, but for them the aesthetic was the main thing that mattered. We could achieve a high satisfaction rate for cosmetic outcome too, and $88 \%$ of patients had rated their outcomes as fully or relatively satisfying.

Our results of septorhinoplasty were close to desired outcomes, but inevitably there remained some degrees of deviation in some of our patients. This was the thing that the patients were warned about and we had their consent. The fact is that, patients are somehow OK with these 
minor cosmetic defects in septorhinoplasty outcomes, maybe due to better nasal function they get instead; it seems the basic role of a surgeon is to make a balance between patients' desire and possible outcomes.

Closed septorhinoplasty could correct mean nasal bony component deviation from $17.4^{\circ}$ to $6.4^{\circ}$, and cartilage component from $16.5^{\circ}$ to $8^{\circ}$; that's while open septorhinoplasty corrected mean bony component from $25^{\circ}$ to $5.4^{\circ}$ and cartilage component from $18^{\circ}$ to $5.3^{\circ}$. This means closed septorhinoplasty has the potentiality to correct the bony component deviation averagely up to $63.2 \%$ of its primary angle; this value for cartilage component is up to $53.1 \%$. That's while, the open septorhinoplasty corrects the primary angle of bony component up to $78.4 \%$, and of the cartilage component up to $70.5 \%$. This clarifies that despite the more severe deformity and deviation in open surgery group, the final deviation correction and cosmetic outcome is obviously better and closer to normal than the closed method.

Although aesthetic indexes correction rates had not kept up with the bony and cartilage deviation correction rates in our series of patients, there has been a relative improvement to normal values. This phenomenon may be explained this way: firstly, the extent of facial deformity in these patients was so severe that had taken these cosmetic aspects of their faces undercover, so maintaining all these angles in their optimum degrees was a very hardly achievable matter, as even in patients without facial deformity is so; secondly, surgeons efforts are mainly aimed to correct nasal function in addition to bony and cartilage components deviation. Thus, it is assumed that techniques we used for septorhinoplasty have not been suitable enough to correct all these angles. Finally as a matter of fact, corrections to the angles are worthy as much as correction of deviation itself.

The results of this study, despite of probable shortcomings like lack of randomization and possible limitation regarding of sample size, can propose superiority of open approach in all cases of deviated nose rhinoplasty. However, most of surgeons select open approach for sever deviated nose deformity, the option of open approach for less sever one related to surgeons' preference. But the better results of open approach in sever deviated nose than the results of close approach in minor deviated nose can propose open approach as a more reliable armamentarium in surgeons' had to get better functional and cosmetic results.

\section{Conclusion}

Among different septorhinoplasty methods for deviated nose, open surgery has better outcomes than the closed, especially in those patients with moderate to severe deviations.

\section{REFERENCES}

[1] H. S. Byrd, J. Salomon and J. Flood, "Correction of the Crooked Nose,” Plastic and Reconstructive Surgery, Vol. 102, No. 6, 1998, pp. 2148-2157. doi:10.1097/00006534-199811000-00055

[2] J. P. Gunter and R. J. Rohrich, "Management of the Deviated Nose. The Importance of Septal Reconstruction," Clinics in Plastic Surgery, Vol. 15, No. 1, 1988, pp. 43-55.

[3] R. P. TerKonda and J. M. Sykes, "Repairing the Twisted Nose," Otolaryngologic Clinics of North America, Vol. 32, No. 1, 1999, pp. 53-64. doi:10.1016/S0030-6665(05)70115-8

[4] R. J. Rohrich, "A Practical Classification of Septonasal Deviation and an Effective Guide to Septal Surgery," Plastic and Reconstructive Surgery, Vol. 104, No. 7, 1999, pp. 2210-2212. doi:10.1097/00006534-199912000-00040

[5] R. J. Rohrich, J. P. Gunter, M. A. Deuber and W. P. Adams Jr., "The Deviated Nose: Optimizing Results Using a Simplified Classification and Algorithmic Approach," Plastic and Reconstructive Surgery, Vol. 110, No. 6, 2002, pp. 1509-1525. doi:10.1097/00006534-200211000-00018

[6] H. M. T. Foda, "The Role of Septal Surgery in Management of the Deviated Nose," Plastic and Reconstructive Surgery, Vol. 115, No. 2, 2005, pp. 406-415. doi:10.1097/01.PRS.0000149421.14281.FD

[7] W. Gubisch, “The Extracorporeal Septum Plasty: A Technique to Correct Difficult Nasal Deformities," Plastic and Reconstructive Surgery, Vol. 95, No. 4, 1995, pp. 672-682. doi:10.1097/00006534-199504000-00008

[8] G. M. Johnson and J. R. Anderson, "The Deviated Nose- Its Correction,” The Laryngoscope, Vol. 87, No. 10, 1977, pp. 1680-1684.

[9] J. Porter and D. M. Toriumi, "Surgical Techniques for Management of the Crooked Nose," Aesthetic Plastic Surgery, Vol. 26, Suppl. 1, 2002, S18.

[10] J. J. Daele, E. Leruth and Y. Goffart, “Consensus in Rhinoplasty,” B-ENT, Vol. 6, Suppl. 15, 2010, pp. 109-113.

[11] G. Hubin and J. J. Daele, "Rhinoplasty Outcome Measurement,” B-ENT, Vol. 6, Suppl. 15, 2010, pp. 103-108.

[12] D.-H. Park, T.-M. Kim, D.-G. Han and K.-Y. Ahn, "Endoscopic-Assisted Correction of the Deviated Nose," Aesthetic Plastic Surgery, Vol. 22, No. 3, 1998, pp. 190-195. doi:10.1007/s002669900190

[13] N. Fanous, "Unilateral Osteotomies for External Bony Deviation of the Nose," Plastic and Reconstructive Surgery, Vol. 100, No. 1, 1997, pp. 115-123. doi:10.1097/00006534-199707000-00021

[14] M. Mendelsohn, "Straightening the Crooked Middle Third of the Nose," Archives of Facial Plastic Surgery, Vol. 7, No. 2, 2005, pp. 74-80. doi:10.1001/archfaci.7.2.74

[15] A. T. Pontius and J. L. Leach, "New Techniques for Management of the Crooked Nose," Archives of Facial Plastic Surgery, Vol. 6, No. 4, 2004, pp. 263-266.

[16] M. Sadeghi, B. Saedi, A. Sazegar and M. Amiri, "The Role of Columellar Struts to Gain and Maintain Tip Projection and Rotation: A Randomized Blinded Trial,” Ameri- 
can Journal of Rhinology \& Allergy, Vol. 23, No. 6, 2009, pp. e47-e50.

[17] M. B. Constantian, “An Algorithm for Correcting the
Asymmetrical Nose,” Plastic and Reconstructive Surgery, Vol. 83, No. 5, 1989, pp. 801-811.

doi:10.1097/00006534-198905000-00006 